\title{
Correction to: Lentinus crinitus basidiocarp stipe and pileus: chemical composition, cytotoxicity and antioxidant activity
}

\author{
Míria B. D. Bertéli ${ }^{1}$. Olavo B. Q. Oliveira Filho ${ }^{1}$. Janyeli D. S. Freitas ${ }^{1}$. Wanessa C. Bortolucci ${ }^{1}$. Gustavo R. Silva ${ }^{2}$. \\ Zilda C. Gazim ${ }^{1}$ - Francislaine A. R. Lívero ${ }^{2}$ Evellyn C. W. Lovato ${ }^{3}$. Juliana S. Valle ${ }^{1}$ Giani A. Linde ${ }^{1}$ Lillian Barros ${ }^{4}$. \\ Filipa S. Reis ${ }^{4} \cdot$ Isabel C. F. R. Ferreira ${ }^{4} \cdot$ Luzia D. Paccola-Meirelles $^{1} \cdot$ Nelson B. Colauto $^{1}$ (D)
}

Published online: 10 April 2021

(๖) The Author(s), under exclusive licence to Springer-Verlag GmbH Germany, part of Springer Nature 2021

\section{Correction to: European Food Research and Technology https://doi.org/10.1007/s00217-021-03713-1}

In the original publication of the article, the spelling of 2 authors' names were published with an error.

"Juliana S. Silveira" (incorrect) should be "Juliana S. Valle" and "Lilian Barros" (incorrect) should be "Lillian Barros".

The original article has been updated with the correct names.
Publisher's Note Springer Nature remains neutral with regard to jurisdictional claims in published maps and institutional affiliations.

The original article can be found online at https://doi.org/10.1007/ s00217-021-03713-1.

Nelson B. Colauto

nelsonbcolauto@gmail.com

1 Laboratory of Molecular Biology, Graduate Program in Biotechnology Applied to Agriculture, Universidade Paranaense, Praça Mascarenhas de Moraes, 4282, Umuarama, PR, P.O. Box 224, 87.502-210, Brazil

2 Laboratory of Preclinical Research of Natural Products, Graduate Program in Medicinal Plants and Phytotherapics in Basic Attention, Graduate Program in Animal Science with Emphasis on Bioactive Products, Universidade Paranaense, Umuarama, PR, Brazil

3 Laboratory of Neurosciences, Graduate Program in Medicinal Plants and Phytotherapics in Basic Attention, Universidade Paranaense, Umuarama, PR, Brazil

4 Centro de Investigação de Montanha (CIMO), Instituto Politécnico de Bragança, Campus de Santa Apolónia, Bragança 5300-253, Portugal 